\title{
Original $\mid$ EXTRA SKELETAL EWING'S SARCOMA FAMILY OF TUMORS IN Article ADULTS. ANALYSIS OF 57 PATIENTS FROM A SINGLE INSTITUTION
}

\section{Amr EL Weshi' ${ }^{1}$, Ayman Allam², Dahish Ajarim', Fouad Al Dayel ${ }^{3}$, Rajeev Pant ${ }^{4}$, Shouki Bazarbashi $^{1}$ and Muhammed Memon ${ }^{1}$}

${ }^{1}$ Departments of Medical Oncology, ${ }^{2}$ Radiation Oncology, ${ }^{3}$ Pathology and ${ }^{4}$ Orthopedics,

King Faisal Specialist Hospital and Research Center, Riyadh, Saudi Arabia

\section{ABSTRACT}

Introduction: Extraskeletal Ewing's Sarcoma (EES) is a rare form of soft tissue sarcoma. To assess the outcome and the prognosis of adult patients presenting with EES treated with multi-modality therapy.

Patients and Methods: All EES patients older than 15 years referred to our institution between January 1995 and December 2004.

Results: A total of 57 patients were identified. Their median age at diagnosis was 20 years (range, 15-57). The median size of primary tumor was $11 \mathrm{~cm}$ (range, $4-30 \mathrm{~cm}$ ). Eighteen patients (31\%) had metastatic disease at presentation. Wide surgical resection with negative margins was achieved in 23 cases. Chemotherapy consisting of vincristine, adriamycin, ifosfamide, actinomycin-D was administered in 50 patients. Radiotherapy was delivered in 37 patients. Forty-one patients achieved complete remission and 16 progressed on therapy. Nineteen (46\%) patients relapsed. Local recurrence was encountered in 14 patients. At a median follow-up of 30 months (range 6-123 months), the 5-year event free survival (EFS) and overall survival (OS) rates were 35\% and 48\% respectively. Metastases at presentation and tumor size correlated significantly with OS on multivariate analysis. EES is an aggressive type of tumor with high incidence of local recurrence and distant metastasis. The outcome of adult EES is not unlike that of skeletal Ewing's sarcoma in terms of response to multi-modality treatment and the prognostic factors influencing treatment outcome. Adequate surgical resection, aggressive chemotherapy and adjuvant local radiation therapy, when indicated, constitute the optimal treatment to achieve the best results in this rare type of disease.

Key Words: Ewing's, prognosis, chemotherapy, survival

Corresponding Author: Amr El-Weshi, MD, E- mail: El weshiamr@ yahoo.com

\section{INTRODUCTION}

The Ewing's sarcoma family of tumors (ESFT) includes classic Ewing's sarcoma (ES) of bone, extraskeletal Ewing's sarcoma (EES), Askin's tumors of the chest wall and primitive neuroectodermal tumors (PNET) of bone or soft tissues. These small round cell tumors are treated similarly because of compelling evidence supporting the hypothesis that they all share a common neural histiogenesis and tumor genetics ${ }^{1}$. The genetic hallmark of ESFT is the presence of the translocation, $\mathrm{t}(11 ; 22)$ (q24; q12) which creates the EWS/FLI1 fusion gene and results in the expression of a chimeric protein. They have a common cell surface marker CD99 (product of MIC-2 gene). The term extraskeletal Ewing's sarcoma (EES) was introduced in 1969 by Tefft et al. ${ }^{2}$ EES is a rare disease that may develop in soft tissues at any location. The most common sites of occurrence are the trunk, extremities and retroperitoneum ${ }^{3,4}$. Although EES is a soft tissue primary tumor, it can cause changes in the cortex of adjacent bone $^{2,4}$. The disease is relatively more common in adults and is associated with a particularly poor prognosis in some series ${ }^{4,5}$. Because of the rarity of EES, very few clinical studies are available that describe the clinical course, therapeutic approaches and prognostic factors. To the best of our knowledge, there are no published series analyzing a relatively large number of adult patients with EES. This has prompted this report to elucidate the clinical features, the management and the outcome of 57 cases with this disease treated at King Faisal Specialist Hospital and Research Center (KFSH and RC) over a 10year period. We also provide a concise comparison of the current series with others reported in the literature.

\section{PATIENTS AND METHODS}

Between January 1995 and December 2004, the medical records and pathology data of all adult patients (age $>15$ years) with newly diagnosed EES were retrospectively reviewed. Institutional Review Board approval was obtained prior to data collection. The pathologic material was reviewed by one of the authors. Hematoxylin and eosin and periodic acidSchiff stained slides were available for review in all cases. Sheets of uniform primitive malignant cells with scanty cytoplasm containing glycogen were the typical morphological features of ES. Lobular pattern, mitosis and fibrous background were seen in most of the cases. A panel of immunohistochemical stains including CD99, 
synaptophysin, chromogranin, neuron specific enolase, NFP, S-100, vimentin, leukocyte common antigen (LCA), cytokeratine (AE1/AE3), desmin and actin were performed. All cases showed diffuse membranous stain for CD99. Tumors classified as ES/PNET when expressed $>2$ neuronal markers. In only few cases, electron microscopy ${ }^{7}$ and cytogentic studies ${ }^{2}$ were used to confirm the diagnosis. Data were gathered with regard to age at diagnosis, gender, tumor site and size, clinical stage, surgical modality and resection margins, induction and adjuvant chemotherapy (CT) regimen, number of CT cycles, histologic response to induction CT, radiotherapy (RT) dose and treatment outcome. Only patients who had adequate clinical data for treatment and follow up were selected.

\section{Clinical evaluation:}

All patients were clinically staged at the time of diagnosis with history and physical examination, routine laboratory studies, chest radiograph, imaging studies of the primary site with plain $\mathrm{x}$-ray and magnetic resonance imaging (MRI) \pm computerized axial tomography scan. Cases with any bone involvement were excluded. Metastatic work up included (CT) scan of chest, bone scan and bone marrow biopsy. Routine pretreatment cardiac assessment including clinical examination, EKG and echocardiogram was done for all patients.

\section{Response definition and survival:}

Clinical assessment, appropriate imaging studies, and pathologic data available on the surgical specimens all together helped in defining response evaluation. A complete response (CR) was defined as a complete resolution of all objective evidence of disease for at least 4 weeks following treatment. Partial response (PR) was defined as a decrease of $50 \%$ or more in the product of the largest two perpendicular diameters of measurable disease, with no progression in other lesions for at least 4 weeks. Progressive disease was defined as an increase of more than $25 \%$ of at least one bi-dimensionally measurable lesion and /or the appearance of new lesion.

Event free survival (EFS) was calculated from the date of diagnosis till the date of disease progression, relapse, death or last follow-up visit. Overall survival (OS) was calculated from the date of diagnosis to the date of death or last follow-up. EFS and OS were estimated using the Kaplan-Meier method, together with 95\% confidence intervals (CIs). Univariate analysis was performed to assess if any prognostic variables conferred an improved survivorship. Cumulative survival rates were compared by the log-rank test with p-values $<0.05$ considered to be significant. Factors that significantly predicted survival rate in the univariate model were then studied in a multivariate analysis using Cox' proportional hazards model. SPSS statistical software version 10.0 (SPSS Inc, Chicago, IL) was used for the analysis.

\section{RESULTS}

\section{Patients characteristics:}

Over a 10-year period, a total of 57 adult patients with EES were seen and treated at KFSH \& RC. Of these 6 were referred for local +/- metastatic relapse after they had surgical resection alone as primary treatment. All of the remaining 51 patients were referred for initial management. Patients had a median age at diagnosis of 20 years (range, 15- 57 years), with male-to-female ratio of 1.6:1. Twenty-seven patients (47\%) presented with a primary soft tissue mass in the trunk. The median tumor size at diagnosis was $11 \mathrm{~cm}$ (rage, 4-30). Thirty-nine(68\%) patients had regionally confined tumor (M0). Four of the eighteen patients who presented with metastatic disease (M1) had involvement of more than one site. Table1 depicts location of the primary disease at presentation and the pre-treatment patient's characteristics.

Table 1: Patients Characteristics.

\begin{tabular}{|c|c|c|}
\hline Factor & No. & $\%$ \\
\hline Total number & \multicolumn{2}{|c|}{57} \\
\hline Age, range (median) & \multicolumn{2}{|c|}{$15-57(20)$} \\
\hline$<20 \mathrm{y}$ & 27 & 47 \\
\hline$>20 y$ & 30 & 53 \\
\hline \multicolumn{3}{|l|}{ Sex } \\
\hline Male & 35 & 61 \\
\hline Female & 22 & 39 \\
\hline \multicolumn{3}{|l|}{ Anatomic location } \\
\hline Extremity & 13 & 23 \\
\hline Central & 44 & 77 \\
\hline Trunk & 27 & \\
\hline Head \& Neck & 7 & \\
\hline Abdomen/Pelvis & 7 & \\
\hline Kidney & 1 & \\
\hline Mediastinum & 1 & \\
\hline CNS & 1 & \\
\hline Size of primary tumor, range (median) & \multicolumn{2}{|c|}{$4-30(11)$} \\
\hline$<10 \mathrm{~cm}$ & 27 & 47 \\
\hline$>10 \mathrm{~cm}$ & 30 & 53 \\
\hline \multicolumn{3}{|l|}{ Histology } \\
\hline Ewing's sarcoma & 31 & 54 \\
\hline PNET & 26 & 46 \\
\hline \multicolumn{3}{|l|}{ Distant metastases } \\
\hline No & 39 & 68 \\
\hline Yes & 18 & 32 \\
\hline \multicolumn{3}{|l|}{ Sites of Metastatic Disease } \\
\hline Lung & 8 & \\
\hline Lymph node & 5 & \\
\hline Bone & 3 & \\
\hline Bone marrow & 3 & \\
\hline Malignant pleural effusion & 2 & \\
\hline CNS & 1 & \\
\hline
\end{tabular}




\section{Therapy, response and treatment failure:}

Systemic CT was administered in all but 2 patients. Fifty patients received combination $\mathrm{CT}$ in their primary treatment plan. A four-drug VAIA regimen was used for all patients. The regimen consisted of vincristine 1.5 $\mathrm{mg} / \mathrm{m}^{2}$ day 1 , doxorubicin $20 \mathrm{mg} / \mathrm{m}^{2} / \mathrm{d}$ alternating with actinomycin-D $0.5 \mathrm{mg} / \mathrm{m}^{2} / \mathrm{d}$; days $1-3$ every other cycle, ifosfamide $2000 \mathrm{mg} / \mathrm{m}^{2} /$ day intravenous infusion days 1 3 with mesna equivalent dose in 3 divided doses, 1 pre and 2 post ifosfamide.

Chemotherapy was given on a three-week schedule and planned to complete a total of fourteen courses. Eight patients had their $\mathrm{CT}$ in adjuvant setting and 42 received part of it as induction prior to definitive local treatment. The median number of cycles administered was 8 (range, 2-14 cycles). In 26 patients (52\%), > 8 cycles were given. Five patients received their first $\mathrm{CT}$ at time of relapse. Surgery alone or combined surgery and RT, or RT alone was used for local control. Wide resection with negative surgical margins was achievable in 23 patients (40\%). Postoperative RT to the primary site was given to 25 patients with doses ranged from 40-57 Gy (median, 50.40 Gy), using 1.8-2 Gy per fraction. The planning target volume encompassed pre CT tumor volume plus a minimal of $2.5 \mathrm{~cm}$ margins all around. Indications for postoperative RT included gross residual disease and positive or close resection margins. The details of therapy are outlined in table 2 .

All patients were evaluable for response. Histologic response of the primary tumor to induction CT was assessed in 30 patients who underwent surgical resection. Twelve patients (40\%) had good histologic response (< $10 \%$ viable tumor cells). In the whole series, forty-one patients (72\%) achieved CR and 16 (28\%) progressed on therapy. Nineteen patients (46\%) relapsed with a median time of relapse of 12 months (range, 1-34 months). Table 3 presents the sites of first disease relapse. Local relapse (LR) rate was 34\%. Of the 14 patients who failed locally, 9 did not receive RT (64\%) and 7 had sub-optimal resection. All the six patients who underwent local resection without adjuvant treatment had LR +/- distant metastases. Five of the seven patients with isolated LR achieved second CR by surgery + CT +/- RT. Salvage chemotherapy regimen consisted of etoposide, ifosfamide and cisplatin (VIP) was given to the patients at progression on /or relapse after VAIA.
Table 2: Details of therapy.

\begin{tabular}{|c|c|c|}
\hline & No. & $\%$ \\
\hline \multicolumn{3}{|l|}{ Type of Surgery } \\
\hline Wide resection & 23 & 40 \\
\hline Sub-optimal resection & 20 & 35 \\
\hline Biopsy only & 14 & 25 \\
\hline \multicolumn{3}{|l|}{ Primary Therapy } \\
\hline $\mathrm{S}+\mathrm{RT}+\mathrm{CT}$ & 24 & 42 \\
\hline $\mathrm{S}+\mathrm{CT}$ & 12 & 21 \\
\hline $\mathrm{RT}+\mathrm{CT}$ & 12 & 21 \\
\hline S & 6 & 10 \\
\hline CT & 2 & 4 \\
\hline $\mathrm{S}+\mathrm{RT}$ & 1 & 2 \\
\hline \multicolumn{3}{|l|}{ Chemotherapy (VAIA Regimen) in } \\
\hline Primary Treatment & 0 & \\
\hline Adjuvant therapy & 8 & 16 \\
\hline Induction therapy & 42 & 84 \\
\hline Number of cycles given (median, range) & \multicolumn{2}{|c|}{$447(8,2-14)$} \\
\hline$>8$ cycles given & 26 & 52 \\
\hline$<8$ cycles given & 24 & 48 \\
\hline \multicolumn{3}{|l|}{ Radiotherapy } \\
\hline Yes & 37 & 65 \\
\hline No & 20 & 35 \\
\hline Dose range (median) & \multicolumn{2}{|c|}{ 40-57 Gy (50.4 Gy) } \\
\hline
\end{tabular}

Table 3: Sites of first relapse in 19 patients

\begin{tabular}{lc}
\hline Site & No. \\
\hline Isolated local recurrence & 7 \\
Local + Distant relapse & 7 \\
Distant relapse & 5 \\
Lung & 8 \\
Bone & 4 \\
CNS & 2 \\
Lymph node & 1 \\
Soft tissue & 1 \\
\hline
\end{tabular}

\section{Follow-up, survival and prognostic factors:}

As of March 2006, with median follow-up of 30 months (range, 6-123), 27 (47\%) of the patients are alive and disease-free; 2 (4\%) are alive with evidence of disease and the remaining 28 (49\%) are dead. All deaths were attributed to disease progression. The median follow-up time for the 29 censored patients in this data set was 65 months (range, 14-123). No second cancers have been reported so far in this cohort of patients. The estimated 5-year OS and EFS for the whole group were $48 \%$ (95\% CI, 34\% - 62\%) and 35\% (95\% CI, 21\% $49 \%$ ) respectively (Figure 1). None of the 18 patients presenting with M1 disease survived beyond 4 years and the 5-year OS for M0 patients was 66\% (95\% CI, 50\%82\%) (Figure 2). 


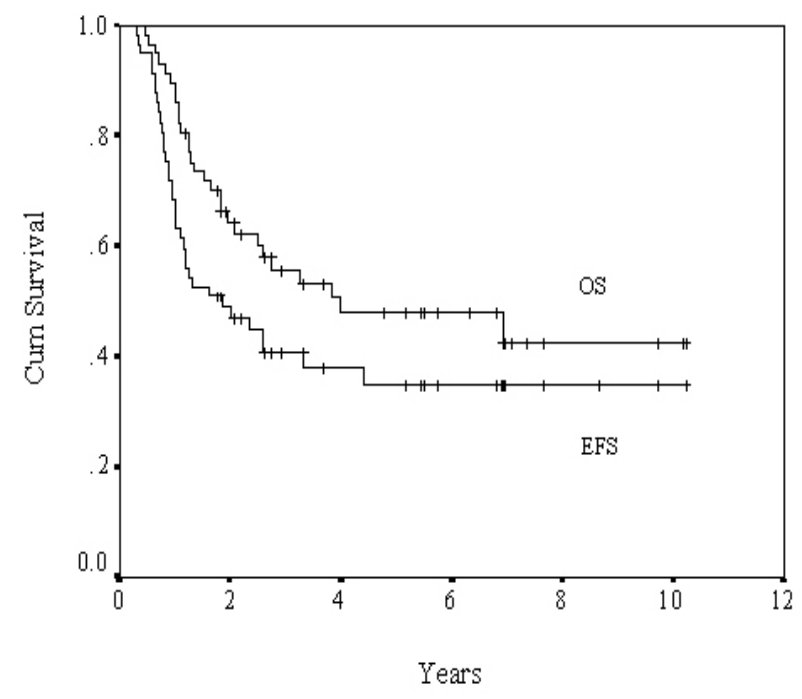

Fig. 1: Overall and Event Free Survival.

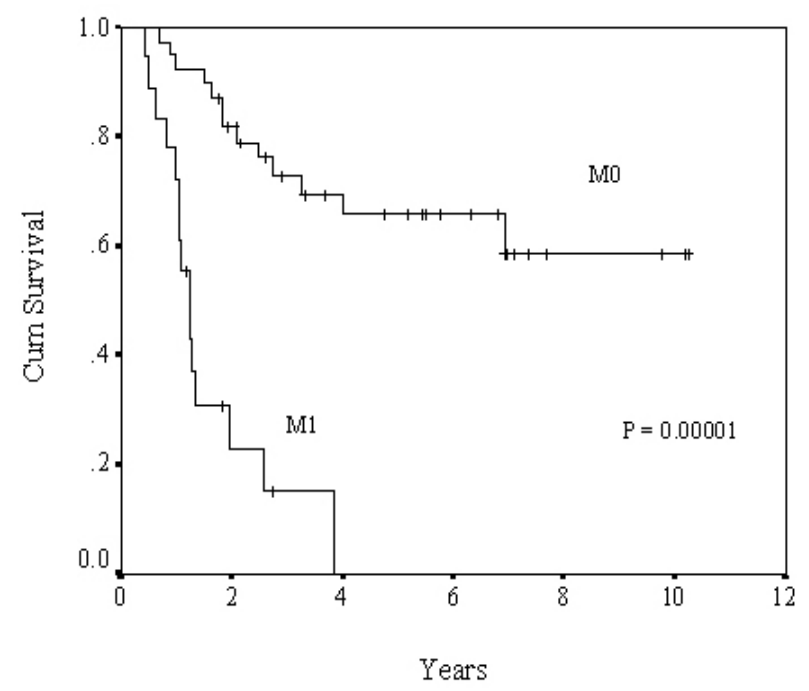

Fig. 2: Overall Survival and Metastasis at Presentation.

Survival rates showed great differences when related to tumor size. Patients with tumors $<10 \mathrm{~cm}$ had the most favorable survival: 70\% (95\% CI, 69\%-89\%) surviving at 10 years (Figure 3). For the 43 patients who underwent a wide or sub-optimal resection (intralesional or contaminated), 5-year survival rates of $69 \%$ (95\% CI, 47\%-90\%) and 49\% (95\% CI, 24\%-74\%) were achieved respectively $(\mathrm{p}=0.05)$. In contrast, the 5-year OS for the patients who had no attempt of resection was only 10\% (95\% CI, 0\%-27\%) (Figure 4). The median survival after distant relapse was 8 months (range 1- 71 months; 95\% CI, 6-10 months), while it was 48 months (range, 3-77 months; 95\% CI, 25-73 months) for patients who experienced isolated LR. Table 4 shows univariate analysis of the impact of various prognostic factors on OS and EFS for all patients. M0 disease at presentation, tumor size $<10 \mathrm{~cm}$, wide excision with negative margins, CT administration of $>8$ cycles, good histologic response to induction CT and primary combined modality treatment (CMT) were found to have a significant influence on both OS and EFS. Radiation therapy had significant effect on EFS (Figure 5) but not on OS. A comparison by multivariate analysis using the Cox proportional hazards model and excluding effects of combined therapy showed both M1 disease and tumor size $>10 \mathrm{~cm}$ to remain statistically significant risk factors for OS (Table 5).

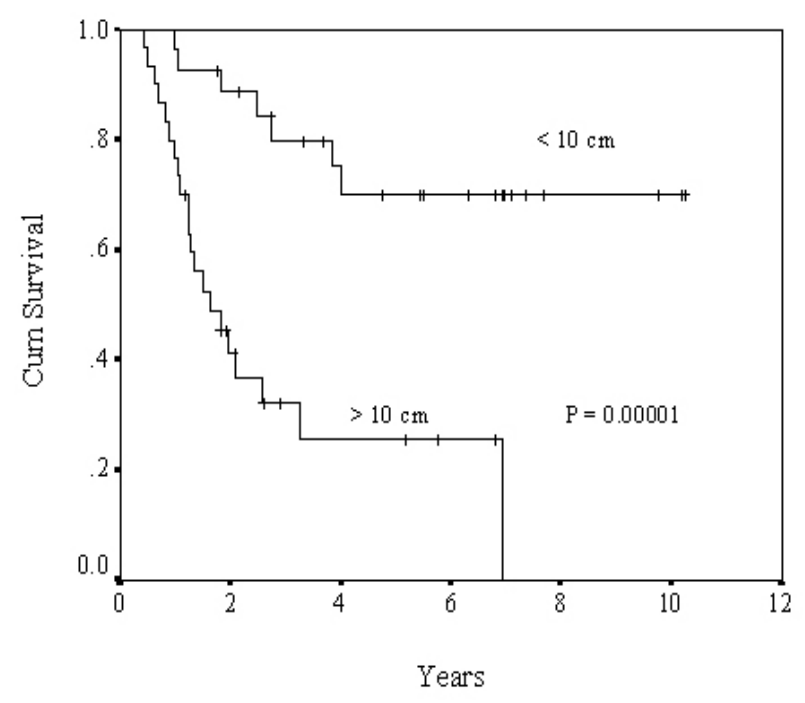

Fig. 3: Overall Survival and Tumor Size.

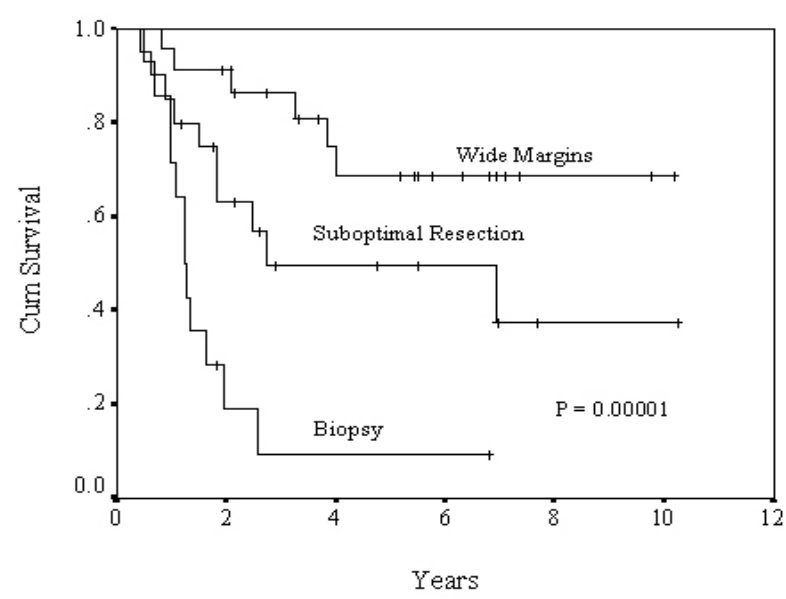

Fig. 4: Overall Survival and Surgical Margin. 
Table 4: Univariate Analysis Of Factors Predicting Overall Survival and Event Free Survival.

\begin{tabular}{|c|c|c|c|c|c|}
\hline Variables & $\begin{array}{l}\text { PATIENT } \\
\text { No }\end{array}$ & $\begin{array}{c}5 \text { YEAR OS } \\
\%\end{array}$ & $\begin{array}{c}\mathbf{P} \\
\text { VALUE }\end{array}$ & $\begin{array}{c}5 \text { YEAR EFS } \\
\%\end{array}$ & $\begin{array}{c}\mathbf{P} \\
\text { VALUE }\end{array}$ \\
\hline \multicolumn{6}{|l|}{ Age } \\
\hline$<20$ & 27 & 58 & NS & 37 & NS \\
\hline$>20$ & 30 & 40 & & 31 & \\
\hline \multicolumn{6}{|l|}{ Sex } \\
\hline Males & 35 & 49 & NS & 36 & NS \\
\hline Females & 22 & 51 & & 41 & \\
\hline \multicolumn{6}{|l|}{ Anatomic location } \\
\hline Central & 44 & 50 & NS & 34 & NS \\
\hline Peripheral & 13 & 42 & & 37 & \\
\hline \multicolumn{6}{|l|}{ Bulky disease (>10 cm) } \\
\hline No & 27 & 70 & .00001 & 53 & .004 \\
\hline Yes & 30 & 26 & & 19 & \\
\hline \multicolumn{6}{|l|}{ Metastases } \\
\hline No & 39 & 66 & .00001 & 49 & .00001 \\
\hline Yes & 18 & 0 & & 0 & \\
\hline \multicolumn{6}{|l|}{ Margins } \\
\hline Wide resection & 23 & 69 & .00001 & 54 & .004 \\
\hline Sub-optimal resection & 20 & 49 & & 28 & \\
\hline Biopsy & 14 & 10 & & 11 & \\
\hline \multicolumn{6}{|l|}{ Chemotherapy } \\
\hline$>8$ cycles & 26 & 68 & .002 & 59 & .02 \\
\hline$<8$ cycles & 24 & 24 & & 24 & \\
\hline \multicolumn{6}{|l|}{ Histologic response } \\
\hline Good & 12 & 71 & .01 & 70 & .02 \\
\hline Poor & 18 & 33 & & 31 & \\
\hline \multicolumn{6}{|l|}{ Radiation } \\
\hline Yes & 37 & 50 & NS & 49 & .004 \\
\hline No & 20 & 45 & & 9 & \\
\hline \multicolumn{6}{|c|}{ Combined Modality Treatment } \\
\hline $\mathrm{S}+\mathrm{RT}+\mathrm{CT}$ & 24 & 68 & .0009 & 67 & .0003 \\
\hline $\mathrm{S}+\mathrm{CT}$ & 12 & 39 & & 22 & \\
\hline $\mathrm{RT}+\mathrm{CT}$ & 12 & 12 & & 11 & \\
\hline
\end{tabular}

Table 5: Multivariate Survival Analysis Using Cox’s Model.

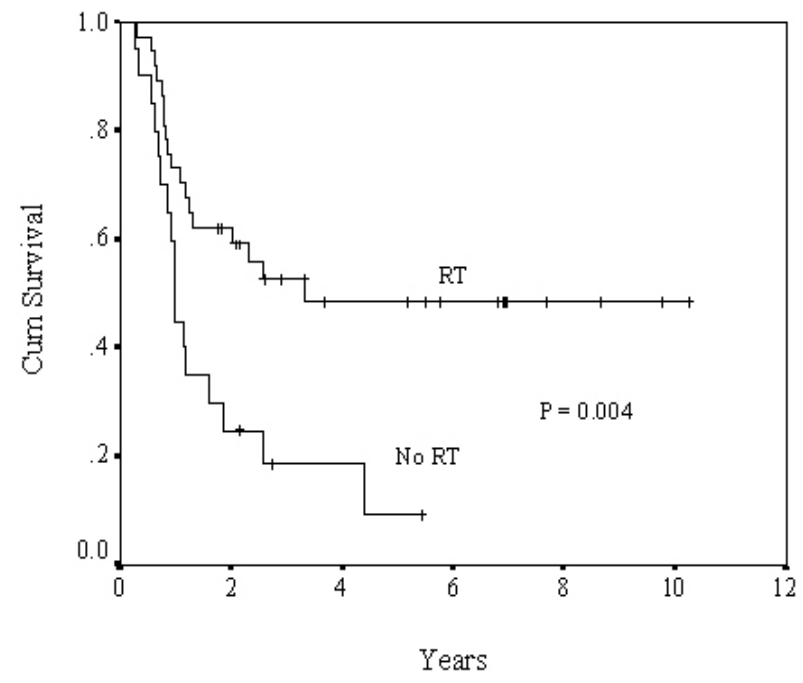

Fig. 5: Event Free Survival and Radiotherapy.

\begin{tabular}{|c|c|c|c|c|c|}
\hline Variable & $\begin{array}{l}\text { Coefficient } \\
\text { (b) }\end{array}$ & SE & $\begin{array}{c}\text { Relative } \\
\text { Risk* }\end{array}$ & $95 \% \mathrm{CI}$ & $\mathbf{P}$ \\
\hline $\begin{array}{l}\text { Disease } \\
\text { extension } \\
\text { Metastases } \\
\text { Localized }\end{array}$ & 2.6079 & .9309 & 13.57 & $2.19-84.13$ & .005 \\
\hline $\begin{array}{l}\text { Size of primary } \\
\text { tumor } \\
\quad>10 \mathrm{~cm} \\
<10 \mathrm{~cm}\end{array}$ & 1.8636 & .7681 & $\begin{array}{c}6.44 \\
1\end{array}$ & $1.43-29.14$ & .015 \\
\hline \multicolumn{6}{|c|}{ *The lower of each category is the reference category. } \\
\hline DISCUSS & & & & & \\
\hline
\end{tabular}

Of the 168 new adult patients with ESFT seen at KFSH \& RC over a 10-year period, 57 (34\%) had extra-skeletal variant. Only a few series in the literature reported on ESFT in adults ${ }^{5-8}$. The incidence of EES in these reports is quite variable ranging from 9-47\%. The clinical features, treatment and prognostic factors of EES are diverse and limited to small reports from few institutions reflecting the rarity of this disease. It has been reported early that EES is relatively more common in adults. A literature review 
of six clinical series published on EES, ${ }^{4,9-13}$ not restricting their analysis to childhood group, demonstrated an adult (>15 years) incidence of $50-91 \%$ (Table 6). Our series is unique in reporting only on adult patients with EES and on having the largest number of patients in this age group. The median age at diagnosis in our patients was 20 years, which is similar to other reported series presenting a wide range of ages ${ }^{4,9-13}$. Sixty one percent of our patients were males, however a sexual predominance was not evident in the literature. The predominant location of EES in our review was the trunk. Locations in the extremities were more frequently observed in some reports ${ }^{9,10,12}$. The incidence of distant metastases in our series (32\%) is among the highest reported in the literature. This is most probably attributed to the large median tumor size $(11 \mathrm{~cm})$ at initial presentation in the present study compared to that reported in the literature $(5-6.5 \mathrm{~cm})^{4,9,10,13}$. The location of metastases at diagnosis was primarily to the lungs, which correspond to the findings of other authors ${ }^{4,10,12}$. Although there is some debate about the management of soft tissue compared with bone Ewing's sarcoma, it is clear that all members of the family share the propensity for metastatic spread. The consistent use of systemic effective CT in the treatment of localized ESFT during the past two decades has increased the 5-year survival rate of $5-10 \%$ to the current rate in excess of $65 \%$, primarily due to elimination of micrometastases. ${ }^{14-19}$ The report from the Mayo Clinic ${ }^{10}$ on 42 EES patients, treated over a 50-year period, demonstrated a significant improvement in the 5-year OS from 28\% before 1970 to $48 \%$ afterwards. Although the optimum combination CT is yet to be established, a four-drug regimen using vincristine, adriamycin, cyclophosphamide and actinomycin-D (VACA) is considered as the standard first line treatment for standard risk patients with localized disease ${ }^{19}$.The integration of ifosfamide $\left(6-9 \mathrm{~g} / \mathrm{m}^{2}\right)$ with dose escalation of adriamycin into the front-line therapy significantly improved the outcome of patients with high-risk localized disease ${ }^{17-19}$. The updated results of the randomized EICESS 92 study, in which etoposide was added to a standard combination regimen for high-risk cases showed a trend towards improved EFS ${ }^{20}$. Despite the larger median tumor size reported in the current series, the 5-year OS and EFS results compare favorably with those reported in the literature (Table 6).

None of the 18 patients presenting with metastases survived beyond 4 years. To date there is little evidence of any benefit from megatherapy regimens with hematopoietic stem cell rescue in the treatment of highrisk localized or metastatic diseases.

Table 6: Literature review of EES clinical series.

\begin{tabular}{|c|c|c|c|c|c|c|c|c|c|c|c|c|}
\hline $\begin{array}{l}\text { Authors / } \\
\text { Year of } \\
\text { Publication / } \\
\text { (Study Period) }\end{array}$ & $\begin{array}{c}\text { No of } \\
\text { Patients/ } \\
\text { No of } \\
\text { Adults }\end{array}$ & $\begin{array}{c}\text { Sex } \\
\mathbf{M} / \mathbf{F}\end{array}$ & $\begin{array}{l}\text { Median } \\
\text { Age } \\
\text { years }\end{array}$ & $\begin{array}{c}\text { Tumor } \\
\text { Size* }^{*} \\
\text { cm }\end{array}$ & $\begin{array}{c}\text { Site } \\
\text { E / C }\end{array}$ & $\begin{array}{l}\text { Stage } \\
\text { IV } \\
(\%)\end{array}$ & $\begin{array}{c}\text { S } \\
\text { No }\end{array}$ & $\begin{array}{c}\text { CT/RT } \\
\text { No }\end{array}$ & $\begin{array}{l}\text { Relapse } \\
\text { Site \& } \\
\text { No }\end{array}$ & $\begin{array}{c}\text { FU } \\
\text { Months }\end{array}$ & $\begin{array}{c}\text { OS } \\
\%\end{array}$ & $\begin{array}{c}\text { DFS } \\
\%\end{array}$ \\
\hline $\begin{array}{l}\text { Angervall et al. } \\
1975,(12 \\
\text { years) }\end{array}$ & $39 / 29$ & 20/19 & 20 & 6 & $11 / 28$ & NR & 33 & $15 / 21$ & $\begin{array}{c}\text { L:1 } \\
\text { M:NR }\end{array}$ & $1-168$ & 37 & NR \\
\hline $\begin{array}{l}\text { Kinsella, et al. } \\
\text { 1983, (5 years) }\end{array}$ & $11 / 10$ & $6 / 5$ & 18 & 6 & $7 / 4$ & $0 \%$ & 6 & $11 / 11$ & $\begin{array}{l}\mathrm{L}: 1 \\
\mathrm{M}: 4\end{array}$ & $\begin{array}{c}46 \\
\text { median }\end{array}$ & NR & 64 \\
\hline $\begin{array}{l}\text { Rud et al. } \\
\text { 1989, (50 } \\
\text { years) }\end{array}$ & $42 / 24$ & $19 / 23$ & 22 & 6.5 & $22 / 20$ & $14 \%$ & 24 & $18 / 24$ & $\begin{array}{l}\text { L: } 16 \\
\text { M: } 24\end{array}$ & $\begin{array}{c}60 \\
\text { mean }\end{array}$ & $\begin{array}{l}38 \\
5 y\end{array}$ & NR \\
\hline $\begin{array}{l}\text { Kushner et al. } \\
\text { 1991, (20 } \\
\text { years) }\end{array}$ & $54 / 29$ & $31 / 23$ & 17 & $>5$ (all) & $5 / 49$ & $20 \%$ & 14 & $36 / 20$ & 22 & $2-180$ & $\begin{array}{c}21 \ddagger \\
5 y\end{array}$ & NR \\
\hline $\begin{array}{l}\text { Siebenrock } \\
\text { et al. } \\
\text { 1996, (27 } \\
\text { years) }\end{array}$ & $34 / 24$ & $21 / 13$ & 20 & $>5$ (15) & $11 / 23$ & $32 \%$ & 32 & $30 / 21$ & $\begin{array}{c}\text { L: } 6 \\
\text { M: } 13\end{array}$ & $\begin{array}{c}84 \\
\text { median }\end{array}$ & $\begin{array}{l}50 \\
5 y\end{array}$ & $\begin{array}{l}33 \\
5 y\end{array}$ \\
\hline $\begin{array}{l}\text { Ahmed et al. } \\
\text { 1998, (18 } \\
\text { years) }\end{array}$ & $24 / 12$ & $13 / 11$ & 15 & $>5$ (13) & $6 / 18$ & $21 \%$ & 19 & $24 / 14$ & $\begin{array}{l}\mathrm{L}: 1 \\
\mathrm{M}: 5\end{array}$ & $\begin{array}{c}64 \\
\text { median }\end{array}$ & $\begin{array}{l}61 \\
5 y\end{array}$ & $\begin{array}{l}54 \\
5 y\end{array}$ \\
\hline $\begin{array}{l}\text { El Weshi et al. } \\
\text { Current study } \\
\text { (10 years) }\end{array}$ & $57 / 57$ & $35 / 22$ & 20 & 11 & $13 / 44$ & $32 \%$ & 43 & $50 / 37$ & $\begin{array}{l}\text { L: } 14 \\
\text { M: } 12\end{array}$ & $\begin{array}{c}30 \\
\text { median }\end{array}$ & $\begin{array}{l}48 \\
5 y\end{array}$ & $\begin{array}{l}35 \\
5 y\end{array}$ \\
\hline
\end{tabular}

Abbreviations: E/C: extremities/central; * median size unless otherwise specified, S: Wide or sub-optimal resection 
ESFT is a radiosensitive, yet this modality does not appear to be curative as a primary local treatment in EES. Kushner et al. ${ }^{11}$ demonstrated a $78 \%$ disease progression at the primary site in 14 patients treated with RT + CT. On the other hand, Kinsella et al. ${ }^{9}$ suggested that wide surgical excision is not necessary for achieving local control and reported a 64\% DFS in 11 patients managed with RT+ CT. Nevertheless, most of the cases (64\%) in their report had extremity lesions with median tumor size of $6 \mathrm{~cm}$. In our series, the 12 patients treated solely with RT+ CT had 5-year EFS of 12\% and local disease progression was observed in $50 \%$ of them. These findings suggest that surgical resection would be the appropriate option for local control in EES.

The rarity of EES lesions makes it difficult to ascertain an optimal management for those tumors. However, better results seem to correlate with more aggressive CMT. In the present study, the 24 patients managed with combination of S+RT+CT had the best treatment outcome with 5-year OS of $68 \%$ versus $39 \%$ for the 12 patients treated with S $+\mathrm{CT}(\mathrm{P}=0.05)$. In the IRS report ${ }^{21}$ of 130 patients with EES in childhood treated in 3 sequential trials, the CMT was tailored according to the clinical groups based on extent of surgery and distant metastases. The 5-year OS rates for the patients treated with $\mathrm{S}+\mathrm{CT}+\mathrm{RT}$ and those treated with S+CT did not differ significantly (90\% vs. $85 \%$ ). The best evidence for the efficacy of the CMT would come from a large multi-institutional randomized prospective clinical trial.

The striking tendency of EES to recur locally was observed by many reviewers. ${ }^{10-12}$ The local recurrence (LR) rate of $34 \%$ in the current study is higher than that reported in most series. One explanation for the relatively high LR rate might be the lack of the routine use of adjuvant postoperative RT, since 9/14 (64\%) patients who developed LR in this study were not offered postoperative RT. In the Mayo Clinic series ${ }^{10}$, the LR rate was $46 \%$. The investigators advised the use of adjuvant RT with all local resections. The current recommendations for postoperative RT include positive or close margins, gross residual disease or poor histologic response to induction $\mathrm{CT}^{22}$ It has been shown that the only patients who had survival advantage from salvage treatment were those with isolated LR that could be treated with a second surgical resection +/- RT and systemic treatment ${ }^{10,23}$. Five cases with isolated LR in our series were successfully salvaged by surgery + CT +/- RT and had a median survival of 83 months.

Whether EES carries a worse prognosis compared to localized ES of bone has been an issue of controversy in some reports ${ }^{5-7,24}$. Our 5-years EFS of $49 \%$ and OS of $66 \%$ for patients with M0 disease compares favorably with the published results ${ }^{7,8}$ on localized ES of bones in adults (35-43\% and 54-60 \% respectively). This is in agreement with the findings of Verrill et al. ${ }^{7}$ who reported no difference between EES and primary ES of bones.

In the current study, metastatic disease at presentation and tumor size were the two most important factors significantly influencing treatment outcome on univariate and multivariate analysis. This finding is in complete agreement with most of the literature reporting either on classic ES of bones ${ }^{8,16,19,25}$ or EES. ${ }^{10,21}$

Several authors ${ }^{9,13,21}$ demonstrated a trend for a more favorable OS in EES patients presenting with extremity lesions. Despite a significantly higher percentage of centrally located tumors (78\%) among our patients, their treatment outcome was similar to those with peripheral tumors. This is probably due to uniform aggressive primary CT used along with the ability to achieve complete or suboptimal surgical resection in about $75 \%$ of patients.

The prognostic significance of histologic response to induction CT has been emphasized ${ }^{7,18,19,25}$. In our report, the 5-year EFS rate was $70 \%$ in good responders (< $10 \%$ viable tumor) and $31 \%$ in poor responders ( $\mathrm{P}=$ $.02)$. The study presented by Rosito et al. ${ }^{18}$ demonstrated a significant difference in EFS at 3-yesr for Grade 1 necrosis compared with grades 2 and 3 (49\% versus 97\%). In the French Ewing's study (EW88), EFS for patients with less than 5\% viable tumor, 5\% to 30\% viable tumor, and $>30 \%$ viable tumor was $75 \%$, $48 \%$ and $20 \%$, respectively ${ }^{22}$. These findings elicit the importance of initial aggressive chemotherapy that could maximize the histologic response. However, response to induction CT correlates closely to tumor burden, which is also difficult to separate from site ${ }^{7}$. Furthermore, a histologic criterion of response needs to be unified.

Previous EES studies ${ }^{10,12,13}$ have pointed the prognostic value of adequate surgical resection and its impact on OS. In the present analysis, the 5-year OS of the 24 patients who underwent wide resection with negative microscopic margins was $70 \%$. Similarly, Rud et al. ${ }^{10}$ showed a $69 \%$ OS in 13 patients with M0 disease treated with radical or wide resection. In another series ${ }^{13}$, a 100\% 5-year OS was reported on 9 patients treated by the same approach. Based on these findings, wide resection with negative margins should remain the goal of surgery in EES.

In conclusion, EES is a rare form of soft tissue sarcoma. The results of the present study demonstrate that EES is an aggressive disease with high incidence of LR and distant metastases. Metastases at presentation and bulk of disease are the most important independent prognostic factors influencing the treatment results. The outcome of adult EES is similar to that of skeletal ES. Non-mutilative surgical treatment with negative resection margins together with the use of aggressive combination CT and postoperative RT when indicated are essential to achieve best chance of cure in this rare type of disease. 


\section{REFERENCES}

1. Ambros IM, Ambros PF, Strehl S, Kovar H, Gadner H, Salzer Kuntschik M. MIC2 is a specific marker for Ewing's sarcoma and peripheral primitive neuroectodermal tumors. Evidence for a common histogenesis of Ewing's sarcoma and peripheral primitive neuroectodermal tumors from MIC2 expression and specific chromosome aberration. Cancer 1991 Apr 1;67(7):188693.

2. Tefft M, Vawter GF, Mitus A. Paravertebral "round cell" tumors in children. Radiology 1969 Jun;92(7):1501-9.

3. Granowetter L, West DC. The Ewing's sarcoma family of tumors: Ewing's sarcoma and peripheral primitive neuroectodermal tumor of bone and soft tissue. Cancer Treat.Res. 1997;92:253-308.

4. Angervall L, Enzinger FM. Extraskeletal neoplasm resembling Ewing’s sarcoma. Cancer 1975 Jul;36(1):240-51.

5. Siegel RD, Ryan LM, Antman KH. Adults with Ewing's sarcoma. An analysis of 16 patients at the Dana-Farber Cancer Institute. Am.J.Clin.Oncol. 1988 Dec;11(6):614-7.

6. Sinkovics JG, Plager C, Ayala AG, Lindberg RD, Samuels ML. Ewing sarcoma: Its course and treatment in 50 adult patients. Oncology 1980;37(2):114-9.

7. Verrill MW, Judson IR, Harmer CL, Fisher C, Thomas JM, Wiltshaw E. Ewing's sarcoma and primitive neuroectodermal tumor in adults: Are they different from Ewing's sarcoma and primitive neuroectodermal tumor in children? J.Clin.Oncol. 1997 Jul;15(7):2611-21.

8. Fizazi K, Dohollou N, Blay JY, Guerin S, Le Cesne A, Andre F, et al. Ewing's family of tumors in adults: Multivariate analysis of survival and long-term results of multimodality therapy in 182 patients. J.Clin.Oncol. 1998 Dec;16(12):3736-43.

9. Kinsella TJ, Triche TJ, Dickman PS, Costa J, Tepper JE, Glaubiger D. Extraskeletal Ewing's sarcoma: Results of combined modality treatment. J.Clin.Oncol. 1983 Aug;1(8):489-95.

10. Rud NP, Reiman HM, Pritchard DJ, Frassica FJ, Smithson WA. Extraosseous Ewing's sarcoma. A study of 42 cases. Cancer 1989 Oct 1;64(7):1548-53.

11. Kushner BH, Hajdu SI, Gulati SC, Erlandson RA, Exelby PR, Lieberman PH. Extracranial primitive neuroectodermal tumors. The Memorial Sloan-Kettering Cancer Center experience. Cancer 1991 Apr 1;67(7):1825-9.

12. Siebenrock KA, Nascimento AG, Rock MG. Comparison of soft tissue Ewing's sarcoma and peripheral neuroectodermal tumor. Clin.Orthop.Relat.Res. 1996 Aug(329):288-99.

13. Ahmad R, Mayol BR, Davis M, Rougraff BT. Extraskeletal Ewing's sarcoma. Cancer 1999 Feb 1;85(3):725-31.
14. Grier H, Krailo M, Tarbell M. Adding ifosfamide and etoposide to vincristine, cyclophosphamide, adriamycin and actinomycin improves outcome in non-metastatic Ewing's and PNET: Update of CCG/POG study. Med.Pediatr.Oncol. 1996;32:193.

15. Wexler LH, DeLaney TF, Tsokos M, Avila N, Steinberg SM, Weaver McClure L, et al. Ifosfamide and etoposide plus vincristine, doxorubicin, and cyclophosphamide for newly diagnosed Ewing’s sarcoma family of tumors. Cancer 1996 Aug 15;78(4):901-11.

16. Verrill MW, Judson IR, Wiltshaw E, Thomas JM, Harmer CL, Fisher C. The use of paediatric chemotherapy protocols at full dose is both a rational and feasible treatment strategy in adults with Ewing's family tumours. Ann.Oncol. 1997 Nov;8(11):1099105.

17. Craft A, Cotterill S, Malcolm A, Spooner D, Grimer R, Souhami $\mathrm{R}$, et al. Ifosfamide-containing chemotherapy in Ewing's sarcoma: The Second United Kingdom Children's Cancer Study Group and the Medical Research Council Ewing's Tumor Study. J.Clin. Oncol. 1998 Nov;16(11):3628-33.

18. Rosito P, Mancini AF, Rondelli R, Abate ME, Pession A, Bedei L, et al. Italian Cooperative Study for the treatment of children and young adults with localized Ewing sarcoma of bone: a preliminary report of 6 years of experience. Cancer 1999 Aug 1;86(3):421-8.

19. Paulussen M, Ahrens S, Dunst J, Winkelmann W, Exner GU, Kotz R, et al. Localized Ewing tumor of bone: Final results of the cooperative Ewing's Sarcoma Study CESS 86. J.Clin.Oncol. 2001 Mar 15;19(6):1818-29.

20. Paulussen M, Craft A, Lewis I. Ewing tumor of bone-updated report of the European Intergroup Cooperative Ewing's Sarcoma Study EICESS 92. Ewing tumor of bone-updated report of the European Intergroup Cooperative Ewing's Sarcoma Study EICESS 92. ; 2002; 21 (393a): 1568

21. Raney RB, Asmar L, Newton WA,Jr, Bagwell C, Breneman JC, Crist W, et al. Ewing's sarcoma of soft tissues in childhood: A report from the Intergroup Rhabdomyosarcoma Study, 1972 to 1991. J.Clin.Oncol. 1997 Feb;15(2):574-82.

22. Oberlin O, Deley MC, Bui BN, Gentet JC, Philip T, Terrier P, et al. Prognostic factors in localized Ewing's tumours and peripheral neuroectodermal tumours: the third study of the French Society of Paediatric Oncology (EW88 study). Br.J.Cancer 2001 Nov 30;85(11):1646-54.

23. Rodriguez Galindo C, Billups CA, Kun LE, Rao BN, Pratt CB, Merchant TE, et al. Survival after recurrence of Ewing tumors: The St Jude Children’s Research Hospital experience, 1979-1999. Cancer 2002 Jan 15;94(2):561-9.

24. Krasin MJ, Davidoff AM, Rodriguez Galindo C, Billups CA, Fuller CE, Neel MD, et al. Definitive surgery and multiagent systemic therapy for patients with localized Ewing sarcoma 
family of tumors: Local outcome and prognostic factors. Cancer 2005 Jul 15;104(2):367-73.

25. Bacci G, Ferrari S, Bertoni F, Rimondini S, Longhi A, Bacchini $\mathrm{P}$, et al. Prognostic factors in nonmetastatic Ewing's sarcoma of bone treated with adjuvant chemotherapy: Analysis of 359 patients at the Istituto Ortopedico Rizzoli. J.Clin.Oncol. 2000 Jan;18(1):4-11. 